\title{
Research on Innovation of Organization Mode of Special Subject Education in Universities
}

\author{
Junxue Zhang ${ }^{1}$ and Shuang Wang ${ }^{1}$ \\ ${ }^{1}$ The department of Institute of Politics, Xi'an University of Arts and Science,710065
}

Keywords: Primary Organizations; Special Education; MOOC; Models

\begin{abstract}
With the continuous development of the times, the pattern and form of higher education in China are constantly moving forward. Under the background of the new era, the development and innovation of the grass-roots organizations in universities have been incorporated into the planning of higher education and development, and the grass-roots organizations in Colleges and universities are the new trend of higher education. This paper focuses on the construction of grass-roots organizations in Colleges and universities, and probes into and studies some problems concerning the construction of grass-roots organizations.
\end{abstract}

\section{Introduction}

Education has always been the focus of attention, and among them, higher education is the most important step in training talents. The grass-roots organizations in Colleges and universities play an irreplaceable role in the implementation of higher education. The grass-roots organizations in universities include various administrative organizations, student organizations and so on in the University system. In the early stage of higher education development in China, the construction of grass-roots organizations has not been paid enough attention, which leads to the fact that school education and students' subjects cannot be integrated in depth, and the educational objectives and the means of implementation are out of line. In recent years, China's colleges and universities have been fully aware of the importance of the construction of grass-roots organizations, focus on ideology, teaching, employment and other aspects of building suitable for higher education under the new situation of the new construction of grass-roots organization mode.

\section{The Main Problems Existing in the Construction of Grass-Roots Organizations in Universities}

Any organization is set with a specific goal, and the development of the organization is based on the realization of the goal. The existence and development of an organization must be institutionalized. As a national talents training base, shouldering the idea from a person, academic training, target support task of modernization construction, the construction of grass-roots organizations must have the appropriate institutional arrangements for the school characteristics and development theory. From the shape of the ideological level, we should focus on strengthening the cultivation of basic administrative organizations, grassroots service organizations, social organizations and build in higher education system, this is the ideological construction of the most important and basic unit. In the academic, university education system should start from the research and teaching tasks, from all aspects of teaching, such as the reform of the course structure, scale, function and so on, all in order to enhance the vitality, improve the innovation capacity of grassroots academic organizations, academic organizations as the starting point and end point.

In recent years, some achievements have been made in the construction of grass-roots organizations in Colleges and universities, but there are still many problems, which can be summed up as follows:

Grassroots Organizations form a Single Activity. The problem of single form of activity has been criticized by the educational circles in our country, especially in the field of ideological education. As far as the organizational forms are widely used, it is no more than the traditional and conservative aspects of lectures, subjects and classes. These forms of organization are simple and boring, and they are very different from the way students enjoy it. It is very difficult to arouse 
students' interest and sympathy. Young students at the forefront to accept new things and new ideas, they hold the traditional attitude often mainly criticism, new things and new ways are to maximize attract their attention. Today, with the development of globalization and information technology with young students as the main body, single and backward activities have seriously hindered the implementation of educational ideas and the implementation of educational objectives.

The Evaluation System is Backward. The evaluation system is a feedback system that should be provided for the success of an activity organization. The feedback system includes not only the organizers of the activities, but also the participants. Throughout our evaluation system, all activities organizers as the center, students are only passive participation in activities. This kind of cramming education method is similar to all the traditional teaching evaluation system based on the achievement theory, but it usually has little effect. A scientific evaluation system cannot ignore the construction of feedback system, so as to achieve the timely adjustment, timely correction, timely summing up, evolving, and ultimately achieve tacit coordination education and education of the party.

Lack of Effective Incentive System. Incentive System is Divided into Material Reward and Spiritual Encouragement. In teaching, we have built a set of effective incentive system, such as students to participate in various competition activities, once a good position, followed by both material incentives, but also spiritual encouragement. But in other fields, the incentive system of other disciplines is still imperfect.

\section{The Important Role of Grass Roots Organizations in Special Education in Universities}

Grassroots organizations are a wide range of forms of existence, and grass-roots organizations play an important role in special education in universities. The role played by grass-roots organizations in special education in Colleges and universities is mainly divided into the following three aspects:

The Grass Roots Organizations have a Clear Division of Labor, and some grass-roots organizations are the basis of school administration work. Under the leadership of the school, grass-roots organizations shoulder the important responsibilities of organizing students directly in Colleges and universities, guiding students, organizing students and uniting students, and implementing policies and policies to the grass roots. Strengthening the construction of certain grass-roots organizations is an important way to strengthen ideological education, and is an important measure to build a harmonious campus and maintain the stability of colleges and universities. It has effectively promoted the reform and development of schools.

Primary Organizations Play a Connecting Role in Thematic Education. The grass-roots organizations use their own organizational characteristics, which can further clarify the requirements of special education, and organize special education to implement details; In the meantime, we can concentrate on the subject groups of the special education, collect the problems encountered in the education and feedback the opinions, and deal with them in a timely manner.

The Relationship between the Leadership and the Leader is unitary, and the relationship between the leadership and the leader exists, and there is a work relationship and there is a relationship between work and life. Grassroots organizations can make full use of their unique hierarchy, play a vanguard role in the special education officer, education teaching place constantly, constantly into the teaching object of life.

\section{Research on Innovation Mode of Grass Roots Organization Construction}

The research on the innovation way of grass-roots organization construction should focus on three aspects: organization leadership, activity development mode and evaluation system.

Innovation organization leadership, first of all we have to do is to abandon the traditional concept of the system, the priority among priorities serving the students, guide students, encourage students to work, establish a responsibility system, strengthen the organization and leadership, to efficiency in the administrative leadership, the implementation of the operation mechanism of loose, do the guiding role of administration. In the construction and allocation of teachers, we should take 
into account the actual situation and development of the school, combine the long-term goals with the short-term goals, and constantly develop in innovation and innovate in the development.

The development of grass-roots organizations should be based on diversification and effectiveness. Not only to achieve the desired goal of education and teaching, but also to adopt a variety of forms and methods. It is necessary to absorb the essence of traditional education, and not to learn, complacent, new media, new educational ideas, new modes of interaction, new means of communication.

The establishment of evaluation system is a systematic project. The establishment of this system requires the participation of society, schools, teachers and students. The evaluation system should be practical and scientific, objective and operational. At present, many universities adopt the evaluation system which is still ten years ago or even a few decades ago, which is difficult to match the current educational development trend. At the same time, it is difficult to objectively reflect the comprehensive level of students to some extent.

Taking the ideological education field as an example, this paper expounds the innovation of the construction of the basic unit combination.

Young students are in an important stage of the formation and development of world outlook, outlook on life and values. Education in the ideological field cannot be relaxed at all. All countries in the world attach great importance to the ideological education of young students.

The ideological education in America is divided into four parts, including civic education, moral education, legal education, religious education and history education. American Moral Education (including ideological education) attention not only with the relevant knowledge and ideas, but also attaches great importance to the development of students' Ideological and moral aspects of cognition, judgment and reasoning ability, and will explore, independent spirit and balanced interpersonal relationship co attitude training.

The Singapore government regards ideological education as one of the three foundations of the national educational policy (the other two are ability education and bilingual education), which make it a strategic position. Singapore is an immigrant country, and the Singapore government emphasizes national consciousness education and forms common values.

Germany's ideological education has a long history and profound tradition and details, and the German government attaches great importance to it. The Federal Education Center was established in Germany to manage ideological education throughout the country. The focus of the Federal Education Center has always been consistent with social development, national foreign policy and other important issues. It has made a significant contribution to the promotion of national economic development, political stability and national unity.

The ideological and moral standards of our citizens also have higher requirements. Both strict to slim, strict right to exercise self-discipline, and look for a job to be honest, to be honest, to be honest business". Young students, as the builders and successors of the country in the future, cannot relax their demands for the cultivation of their ideological and moral qualities. As the base of national talents training, the cultivation of young students' Ideological and moral accomplishment should be carried out on the strategic level.

The author believes that the grass-roots organizations in strengthening the cultivation of young students ideological and moral education can be innovative ways to take the following:

Strengthen the Contact between Teachers and Students "Three Docking" Mode. To strengthen the relationship between teachers and students is not only the need of teaching and learning, but also higher requirements for educators in the new era. In the subject education, we should attach importance to the three docking relations: teachers docking students, teachers docking students, student backbone docking students. These three kinds of docking relations from top to bottom, from outside and inside, not only the whole layout, but also carefully planned. The connection between teachers and students mainly solves the relationship between teaching and learning. The connection between teaching staff and students mainly reflects the relationship between the service subject and the object of service; Student backbone and students docking, mainly to solve the pioneer model and lead demonstration role. The three docking covers a wide 
range of levels, and once a reasonable organization, fine progress, can achieve the focus of the overall laying of the effect.

MOOC. With the development of modern information technology, the emergence of multimedia and network has brought great convenience for the grass-roots organizations to carry out education and teaching activities. In the field of ideological education, the territory of grass-roots organizations should not be confined to public places such as classrooms, but should be extended to students' lives.

MOOC, also known as Mu class platform, is the world's sudden rise in teaching mode in recent years. Britain's "future learning", "Digital University" in France, and "Mu program" at Tsinghua University and Jiaotong University in China belong to the MOOC.

There are many advantages of MOOC, such as the improvement of teaching quality, the saving of space and time, the expansion of audience and scope, the promotion of teaching reform and the improvement of teaching quality.

The use of MOOC for ideological education, innovative forms, flexible methods for students to create a good self-learning environment. The grass-roots organizations should work hard at the setting of the content of the micro courses, and make every effort to make the MOOC pictures and illustrations, shape and taste, and be able to make the abstract and complex concepts concrete and visualized. This will not only help to improve the students' learning efficiency, but also change the disadvantages of the traditional communication method in a single and boring way, and form a multi - way and multi - channel educational means. At the same time, to increase the amount of information effectively, it is very easy to arouse students' interest and stimulate students' ability to learn autonomously.

Set an Example and Pay Attention to Propaganda and Guidance. The power of an example is endless, and everyone has his or her own examples of admiration and admiration. Grassroots organizations should fully explore and fully play the role of these examples in the ideological and moral cultivation of students, especially the ideological realm, moral realm, able to make a model for others outstanding students.

Student models lead the way. It is in the stage of college students age fearless, and have a rebellious, many times if we will own the concept of force feed them often achieve the opposite effect of education. But student role models are one of them. They have high recognition of student models and are more likely to resonate with ideas and emotions. Usually, the model for students to study hard, strict with oneself and to other three good student model as the goal, will naturally establish a correct outlook on life, values and world view, ideological level and moral realm will gradually close to them. Grassroots organizations should play their own role in coordinating the organization, set up a typical example of propaganda, and promote the correct value orientation among students, so as to achieve the purpose of education and guidance. This guide should make excellent students into their surroundings, let these students really come into the students, let the students to see what is typical, typical which has excellent quality, the only way to make the typical spirit into action more students. Among them, the leadership, organization and coordination of grass-roots organizations play a very important role.

\section{The Mode Innovation will Contribute to the Effect of Special Education and Promote the Construction of Grass-Roots Organizations}

In the new period, the goal of higher education has not only focused on the academic scores of students, but also on the comprehensive quality of students. As the main battlefield of education and teaching, schools shoulder the important task of transporting high-quality talents for the country. As a special form of education development, special education can achieve better teaching effect in a relatively short period of time if it is properly used. The smooth progress of thematic education and the effective coordination with the grass-roots organizations have a close relationship with each other.

Strengthening the construction of grass-roots organizations is the requirement of the characteristics of education and teaching in the new era. At the moment, the education model based 
on quality education is advocated. In this mode, students play a dual role. In this mode, the role of grass-roots organizations in the bridge is particularly prominent.

Strengthening the construction of grass-roots organizations is the key to innovation. Young students have the characteristics of young students in special education in the teaching method and our method to continuous innovation, continuous improvement, and constantly enrich the students are familiar with the latest achievements of way of education. The development of grass-roots organizations and the innovation of methods and methods are not contradictory individuals between the two, but complement each other. Innovation and transformation of ways and means will help grass-roots organizations carry out their work better and embody their functions more efficiently; The development of grass-roots organizations also ensures the organization and implementation of ways and means.

Finally, to strengthen the core of the construction of grass-roots organizations, we must always adhere to the people-oriented concept. This requires not only to continue learning as part of the grass-roots organizations, but also to improve their practical ability to carry out their work. It also requires us to learn to think when we work, to think what others think, to be anxious about what others have to do, to have a strong inner quality, and to have a strong outside ability. With full work enthusiasm and sense of responsibility and sense of mission into the work.

\section{Acknowledgements}

Fund Project: 2015 annual Xi'an social science fund project planning (15WL24) research to deepen the three strict three special education innovation and grassroots party building work study.

\section{References}

[1] Chen Xiaolin, Jiang Heng. Innovative practice of basic teaching organization in Colleges and universities in the new era [J]. Chinese University Teaching, 2013, (08):78-80.

[2] Zhang Lifen. Practice and Reflection on "three docking" in Vocational Education-Taking Hubei Communications Technical College as an example [J]. Industrial \& Science Tribune, 2014, (22):183-184.

[3] Zhou Binfeng, Xie Xinshui, Liu Xingqi. Teaching elements and evaluation of teaching effectiveness in micro class [J]. Modern educational technology, 2015, (09):30-36.

[4] Gan Lihua. Professors at Tsinghua University urge college teachers to be cautious about "high-tech" [N]. China Youth News,2010-10-22(6).

[5] Ye Mengwei. Role of student example in the construction of academic atmosphere in Colleges and Universities [J]. Theoretical observation,2015, (12):112-113.

[6] Liu Jun, My view on new media [J]. Grand View of Advertising, 2009,(6):26 27

[7] Lin Li, The competition strategy of traditional media to new media [J]. News enthusiast, 2012,(12):39 40

[8] Liao Zhexun, On the construction of subject group of curriculum theory in China -- curriculum, teaching materials and teaching methods, 2000, Phase 2

[9] Kang Junming, Literature review of school culture construction -- Journal of Northwest Adult Education, 2012, Phase 5

[10] Lin Lifang, On the Countermeasures of carrying out the "three strict standards" and "loyalty, clean and taking" in Colleges and Universities $[\mathrm{J}]$, Contemporary educational practice and teaching research, 2017(03):240-241

[11] Chen Qing, Fang Yunji. To three strict standards education as an opportunity to promote organ efficiency construction in Colleges and Universities [J], University Logistics Research, 2017(1): $70-72$ 